\title{
O DISCURSO MÍTICO E MEMORIALÍSTICO NOS TEXTOS DE LITERATURA DE EXPRESSÃO AMAZÔNICA PRESENTES NOS TEXTOS DE INGLÊS DE SOUSA, MARIA LÚCIA MEDEIROS E MILTON HATOUM
}

\author{
Cristiane de Mesquita ALVES ${ }^{1}$ \\ José Guilherme de Oliveira CASTRO² \\ Joyce Cristina Farias de AMORIM ${ }^{3}$ \\ Wellingson Valente dos REIS ${ }^{4}$
}

\begin{abstract}
RESUMO
Este trabalho se desenvolve a partir da análise da presença do discurso mítico e memorialístico dentro de três obras da Literatura de expressão amazônica, duas oriundas do Pará: O rebelde de Inglês de Sousa e Quarto de hora de Maria Lúcia Medeiros e outra de Manaus, Dois Irmãos do escritor Milton Hatoum. O recorte para estudo foi alicerçado nas leituras e nas seleções de passagens das obras, tendo como referencial teórico-metodológico a Análise do Discurso nas formações discursivas, ideológicas e a ideologia presentes em Foucault (2013) e Bakhtin (2000); na ideia de horizonte de expectativa da Estética da Recepção de Jauss (1994), nos preceitos acerca da Literatura amazônica em Loureiro (2015); nas questões pertinentes à memória Bosi (1987), Halbwachs (2013), Pêcheux (1999), e sobre o mítico Joseph Campbell (1997), os quais nortearam a realização dessa escrita.
\end{abstract}

Palavras-chave: Análise do Discurso. Literatura Amazônica. Memória. Mítico. Estética da Recepção.

\section{RESUMEN}

En ese trabajo se desarrolla la partir de la análisis de la presencia del discurso mítico y memorialístico dentro de tres obras de la Literatura de expresión amazónica, dos venidas del Pará: El rebelde de Inglês de Sousa y Cuarto de hora de Maria Lúcia Medeiros y otra de Manaus, Dos Hermanos del escritor Milton Hatoum. El recorte para estudio fue basado en las lecturas y en las selecciones de pasajes de las obras, teniendo como referencial teórico-metodológico la Análisis del Discurso en las formaciones discursivas, ideológicas y a ideologia presentes en Foucault (2013) y Bakhtin (2000); en la idea de horizonte de expectativa de la Estética de la Recepción de Jauss (1994), en los precetos a respeto de la Literatura amazónica en Loureiro (2015); en las cuestiones pertinentes a la memoria Bosi (1987), Halbwachs (2013), Pêcheux (1999), y sobre el mítico Joseph Campbell (1997), los cuales nortearan la realización de esa escrita.

Palabras- llave: Análisis del Discurso. Literatura Amazónica. Memoria. Mítico. Estética de la Recepción.

1 Doutoranda em Comunicação, Linguagens e Cultura pelo PPGCL da Universidade da Amazônia. Bolsista Prosup/ Capes. Membro do do Grupo Interfaces do Texto Amazônico. cris.mesquita28@hotmail. com.

2 Doutor em Letras pela PU-

C-RS. Professor Titular da
Universidade da Amazônia. zevone@superig.com.br.

3. Mestra em Comunicação, Linguagens e Cultura pelo PPGCL da Universidade da Amazônia. Professora efetiva da Seduc- PA. joycecrisamorim@yahoo.com.br.

4 Doutorando em Comuni- cação, Linguagens e Cultura pelo PPGCLC da Universidade da Amazônia. Bolsista Prosup/Capes. Professor do Instituto Federal do Pará. Membro do Grupo Interdisciplinar de Pesquisa em Arte, Cultura e Educação e do Grupo Interfaces do Texto Amazônico. wellingsonreis@uol. com.br
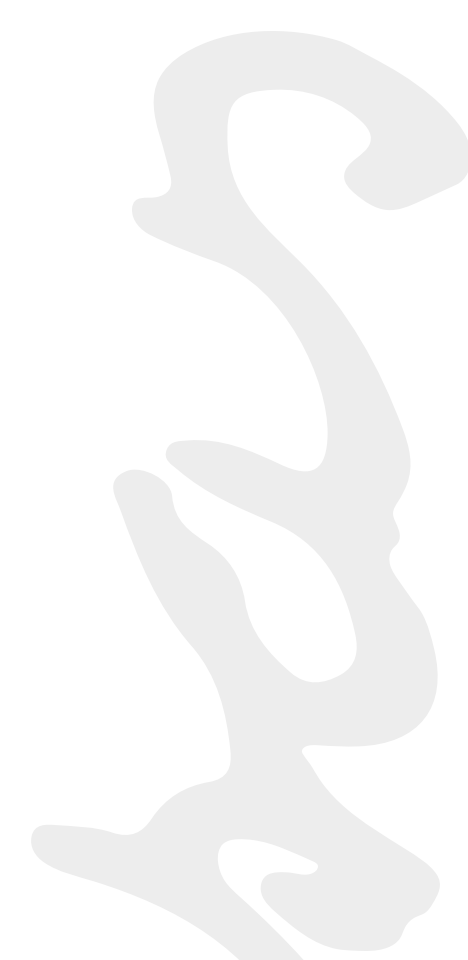
ENTRELAÇANDO DISCURSOS, HORAS, ESPAÇOS E MEMÓRIAS.

Nem tudo o que lemos está escrito.

Frank Smith.

Escrever sobre a literatura, de modo geral, é ler e receber o texto como também uma parte de si, para compreender melhor, não só a leitura específica de um autor/obra, mas também a própria vivência de quem recebe o texto, uma vez que há na relação entre literatura e leitor o nexo entre as obras literárias (JAUSS, 1994), o que configura um processo comunicativo que faz do leitor o destinatário das mesmas. Por esse motivo, para entender as leituras das narrativas míticas presentes nos textos, foi empregado o método de Análise do Discurso proposto por dois autores: Bakhtin e Foucault. O primeiro teórico russo destaca a ideia de que a base de todas as suas teorias discursivas está na constituição histórica e social do sujeito, segundo ele o discurso do sujeito que fala nas obras literárias, embora em seu estudo, destaque o romance, não é um dialeto individual, em contraste a uma linguagem social e, assim, as linguagens das personagens, por serem virtuais, requerem uma difusão social.

Já para Foucault (2013), existe um intrincamento entre um léxico e uma experiência, capaz de mostrar, nos próprios discursos laços, aparentemente fortes que se desfazem entre as palavras e as coisas, e destacam-se em um conjunto de regras, peculiares da prática discursiva. Não se pode tratar os discursos como conjunto de signos (elementos significantes que remetem a conteúdos ou a representações), mas como práticas que formam sistematicamente os objetos de que falam, por isso o campo social deve está inserido na prática discursiva.

Tanto o teórico russo quanto o francês compartilham a ideia de que a o discurso existe a partir de uma prática ou realidade social, e dentre tantos discursos vinculados à sociedade, está indubitavelmente, o discurso literário que entrelaça os discursos e as teorias dos dois teóricos europeus a necessidade que se tem neste estudo, em analisar os discursos memorialísticos e míticos presentes em alguns pontos das obras selecionadas.

A partir do momento que se diz que a prática discursiva é social, na literatura há duas que se relacionam a ficção a partir da recepção da realidade social. A primeira está organizada pelo discurso memorialístico, o qual apresenta a memória como uma relação do corpo "presente com o passado e, ao mesmo tempo, interfere no processo "atual" das representações." (BOSI, 1987, p.9). Por meio dela, o passado mistura-se com as percepções imediatas do presente, ocupando o espaço da consciência, fazendo-se com que a memória "aparece como força subjetiva ao mesmo tempo profunda e ativa, latente e penetrante, oculta e inovadora." (BOSI, 1987, p.9). Esse processo atual das representações (grifo nosso) dos processos memorialísticos tão enfatizados por Bosi (BOSI, 1987, p.9) é uma realidade presente ao longo das obras que se estudam (cada uma de elas com suas peculiaridades, as quais serão abordadas).

Além disso, a relação memória e discurso (COURTINE, 1999) apresenta dois níveis de descrição: o nível da enunciação (o eu-aqui-agora do discurso), correspondente ao intradiscurso, e o nível do enunciado, sob domínio da memória, correspondente ao interdiscurso. Essa divisão é relevante porque diferencia o trabalho do analista do discurso, do trabalho do linguísta. Enquanto a Linguística está ligada ao domínio do texto, a Análise do Discurso entra e sai do texto em busca dos sentidos que nele transitam.

Courtine (1999) afirma que ressoa no domínio da memória somente uma voz sem nome, não encontrando no sujeito, nenhum lugar assinalável. Ele faz uma alusão ao caráter social da linguagem, considerando memória e esquecimento indissociáveis. De fato, é preciso esquecer de algum modo para poder lembrar. Tal como em Pêcheux (1999), a memória é o lugar do conflito, da tensão, da retomada. Não há memória fixa. Não há memória sem esquecimento, pois só se retoma o que se perde. Para Pêcheux (1999), a memória discursiva seria "aquilo que, face a um texto que surge como acontecimento a ler, vem restabelecer os 'implícitos' [...] de que sua leitura necessita: a condição do legível em relação ao próprio legível" (PÊCHEUX, 1999, p. 52). Entretanto, a memória não seria um depósito de implícitos, pois o acon- 
tecimento discursivo novo desloca e desregula os implícitos. A partir disso, o autor postula uma espécie de jogo de força da memória entre a regularização e a desregulação da rede dos implícitos.

Pêcheux (Ibidem) entende a memória como um espaço móvel e não-homogêneo, ela

não poderia ser concebida como uma esfera plena, cujas bordas seriam transcendentais históricos e cujo conteúdo seria um sentido homogêneo, acumulado ao modo de um reservatório: é necessariamente um espaço móvel de divisões, de disjunções, de desdobramentos e de retomadas, de conflitos de regularização.... Um espaço de desdobramentos, réplicas, polêmicas e contra-discursos. (PÊCHEUX, 1999, p. 56).

Além do discurso da memória, há também nas três tessituras uma constância para se referir ao discurso mítico, este empregado como uma forma de representação social, nas comunidades amazônidas, as falas formadas pelo mítico se confundem com as práticas sociais, e como se usa a Literatura nesta pesquisa, por um viés social, compreende-se que o mito, o discurso a partir das representações míticas são intrínsecas ao cotidiano social das personagens, tem-se a consciência que isso ocorre de forma mais constante na oralidade, mas também nos textos de literatura escrita estão presentes, como forma de representatividade de uma comunidade. E isso se sucederá nas três narrativas que se fará uma comparação ligeira sobre a presença do mítico. São elas: o conto O rebelde do livro Contos Amazônicos (1893) do escritor paraense Inglês de Sousa (1853-1918), do conto e livro homônimo, intitulado Quarto de Hora (1994) de Maria Lúcia Medeiros (1942- 2005) e algumas passagens do romance Dois Irmãos (2000) de Milton Hatoum (1952), destacando o discurso mítico presente ao longo dos trechos das tessituras.

\section{ENTRE GUERRA, MEMÓRIA, IDENTIDADE E MITO.}

A minha imaginação exaltava-se com a singularidade, ao mesmo tempo que uma curiosidade feminina me impelia a buscar a última palavra em todos os segredos, a razão de ser de todos os mistérios. (SOUSA, 2005, p. 100).

O rebelde é a narrativa mais extensa do livro Contos Amazônicos (1893) de Inglês de Sousa. E se trata da história do narrador/personagem chamado Luis e sobre a sua grande e conflituosa amizade com Paulo da Rocha. A narrativa tem como contexto histórico a Cabanagem, um período sangrento que assolou o Pará de 1835 a 1840. A obra quebra o horizonte de expectativa do leitor (JAUSS, 1994), ao unir, dois personagens que possuem formações ideológicas tão distintas, no caso Paulo da Rocha, trabalhador, guerrilheiro e Luis, burguês, rico.

Ao narrar sua história, Luis rememora a sua infância contando como a sua amizade com o velho pernambucano começou e marcou a sua vida por inúmeros motivos, principalmente, por tê-lo salvo da morte. Voltando ao tempo, num período de quarenta anos, Luis começa relatando quando viu Paulo da Rocha pela primeira vez e sobre a impressão inexplicável que aquele homem lhe causara. As pessoas de Vila Bela tinham no seu discurso uma formação ideológica muito marcada, onde representava todo o horror ao pernambucano Paulo da Rocha, a quem chamavam o velho do outro mundo, mas Luis possuía uma visão ideológica diferente, talvez por ser criança, admirava aquele homem. Sentia uma ligação muito forte, por aquele senhor que aparentava ter em torno de cinquenta anos, algo que nem o próprio Luis sabia explicar: "O velho ríspido [...], era extremamente bondoso para comigo. Não sei que imã oculto me atraía para aquele mulato [...], de quem meus pais não gostavam, e que inspirava a quase toda a população da vila uma antipatia mesclada de horror." (SOUSA, 2005, p. 99).

Amizade inexplicável até para as pessoas de Vila Bela, pois segundo Luis, "[...] apesar dessa enorme desproporção de idades, ligava-os uma amizade terna, inexplicável para toda a gente" (Ibidem, p. 99). Ao contrário das pessoas de Vila Bela, Luis construiu uma imagem de Paulo da Rocha com a mesma ideia de um

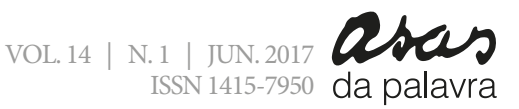


herói, residente nas suas imaginações de menino.

Foi isso mais ou menos o que senti a primeira vez que encontrei no meu caminho o rebelde de 1817, temido e desprezado ao mesmo tempo. [...] Naquele pobre velho uma voz oculta me indicara um herói das antigas lendas que a minha avó me contava à luz mortiça da lamparina de azeite de andiroba, um homem como eu sonhava nos meus devaneios infantis. (SOUSA, 2005, p. 100-101).

No discurso da memória de Luis, percebe-se a presença da ideologia burguesa, para descrever Paulo da Rocha, o narrador utiliza palavras como rebelde e pobre velho, palavras que denotam ao mesmo tempo, distanciamento de classes e pena, por Paulo da Rocha não estar na mesma classe social que ele. No entanto, Paulo da Rocha representa, naquele momento da narrativa, o herói para Luis, pois esse homem configura o que na "mitologia não tem como seu maior herói o homem meramente virtuoso. A virtude não é senão o prelúdio pedagógico da percepção culminante, que ultrapassa todos os pares de opostos." (CAMPBELL, 1997, p. 25).

Corroborando a esse discurso, em Bakhtin (2002), ao discutir a ideia do herói romanesco e épico, pressupõe que a sua ação é sublinhada por sua ideologia, o herói vive e age em seu próprio mundo ideológico (não apenas num mundo épico), ele tem sua própria concepção do mundo, personificada em sua ação e em sua palavra. Entretanto,

por que não se pode descobrir a posição ideológica do personagem e o mundo ideológico que está em sua base, em suas próprias ações e unicamente nelas, sem precisar se representar seu discurso? Não é possível representar adequadamente o mundo ideológico de outrem, sem lhe dar sua própria ressonância, sem descobrir suas palavras. Já que só estas palavras podem realmente ser adequadas à representação de seu mundo ideológico original, ainda que estejam confundidas com as palavras do autor. O romancista pode também não dar ao seu herói um discurso direto, pode limitar-se apenas a descrever suas ações, mas nesta representação do autor, se ela for fundamental e adequada, inevitavelmente ressoará junto com o discurso do autor também o discurso de outrem, o discurso do próprio personagem. (BAKHTIN, 2002, p.137).

A estranha amizade considerada inexplicável tanto para Luis, quanto para toda a sociedade de Vila Bela, dava-se por se considerar absurda a ideia de se imaginar qualquer relação amigável entre aquele que representaria o colonizador e aquele que se configuraria no colonizado, ou seja, Luis era de descendência portuguesa e Paulo da Rocha, mulato/cabano, o que, consequentemente, interfere de forma direta na vida de Luis, desencadeando uma crise, um conflito dentro do seu processo identitário. Pois, pensando na questão lógica da história, como seria possível estes tornarem-se amigos, quando na verdade deveriam ser inimigos? Luis, desde o início revela que o contraditório sempre o atraía. Via-o como herói. Não conseguia vê-lo como inimigo.

O paradoxo é algo marcante nesta relação de amizade, tanto do ponto de vista histórico, quanto pelo ponto de vista do próprio narrador. Do ponto de vista do narrador, este descreve que "tudo no velho do outro mundo contribuía para o excitar a imaginação e avisar o afeto que o inspirava [...] tudo o indicava no pernambucano um personagem ideal fantástico, como ele imaginava os seus heróis". (SOUSA, 2005 , p. 101). Luis sempre viveu "em contradição de sentimentos e de ideias com os que o cercavam" (SOUSA, 2005, p. 100). Já do ponto de vista histórico, o que se percebe é, claramente, a ideia de ódio entre os cabanos e os portugueses que iniciou com a colonização, ou seja, historicamente falando, "o certo é que o branco e o caboclo se haviam jurado um ódio eterno" (SOUSA, 2005, p. 110). Esse ódio é claro e 
vivo na relação entre o cabano Matias Paxiúba e o branco/português Luis Guilherme da Silveira: "tinham-se sempre encontrado inimigos - desde a primeira vez que se viram parecia que todo o ódio das duas raças, a conquistadora e a indígena, se tinha personificado naqueles dois homens, cujos nomes eram grito de guerra de cada um dos partidos adversos." (SOUSA, 2005, p. 111).

Enquanto que na relação entre Paulo da Rocha e Luis, estava vivo apenas na memória deste último, que vivia um conflito interior, pois Luis estava completamente encantado e admirava-se cada vez mais por Paulo da Rocha, porém, isso mudou quando o velho do outro mundo revelara ser um cabano. Luis ficou em crise, pois essa revelação abalara a amizade com Paulo da Rocha, no sentido de que como ele poderia ser amigo daquele homem, considerando ser Luis, português? Na verdade, a história rememorada por Luis era permeada por contradições. O paradoxo no discurso de Luis sugere uma possível crise de identidade, tão discutida por Hall (2000), instaurava-se sobre Luis:

Apesar da simpatia que sentia pelo velho, as suas ideias, os seus sentimentos, contrariavam por tal forma os preconceitos da minha educação, que eu me sentia indignado pela amizade que, apesar de tudo, lhe dedicava. Envergonhava-me a admiração respeitosa que lhe faltava. (SOUSA, 2005, p. 110).

Toda a narrativa é contada construindo no leitor ora impressões positivas, a favor dos portugueses, ora essas impressões recaíam sobre a situação e o objetivo dos cabanos. Impossível não se comover com a situação de Luis e sua família, bem como não se pode ignorar "as causas da cabanagem, a miséria originária das populações inferiores, a escravidão dos índios, a crueldade dos brancos, os inqualificáveis abusos com que esmagam o pobre tapuio, a longa paciência destes" (SOUSA, 2005, p. 120), bem como sabiam estes "que enquanto durasse o predomínio despótico do estrangeiro, $[. .$.$] continuariam vítimas de todas as prepotências, pois que eram brasileiros$ e como tais condenados a sustentar com o suor do rosto a raça dos conquistadores" (SOUSA, 2005, p. 121).

Mesmo com tantas provas de amizade, a dúvida sempre perseguia Luis. Sempre acreditava que em algum momento o velho do outro mundo o levaria para a morte. E com o passar dos anos, Luis já formado e tendo se tornado juiz municipal e delegado de Óbidos, durante uma visita, conversava com o comandante do forte, descobriu que o seu velho amigo encontrara-se preso e ao encontrá-lo no cárcere, Luis sentiu uma estranha emoção a apoderar-se dele. Dois dias depois de conseguir a liberdade, o velho do outro mundo morrera em seus braços, "voou aquela sublime alma para o céu sem murmurar contra os seus algozes" (SOUSA, 2005, p. 140), mas a memória daquele homem viveu para sempre no coração de Luis.

Compreende-se aqui que a amizade entre os dois principais personagens predominou, e prevaleceu sobremaneira aos seus preconceitos, as suas dores, as suas origens, as suas vontades. Uma amizade que nasceu de uma maneira estranha e inexplicável, sobreviveu ao tempo. E sobreviveu graças à vontade e à necessidade que Paulo da Rocha sentiu em cumprir a qualquer custo a promessa que fizera ao pai de Luis, de defender o menino de seus sanguinários inimigos. Quanto ao menino Luis essa amizade prevaleceu, pelo sentimento que se reforçou de admiração, mas principalmente pela gratidão ao seu velho amigo. A identidade de Luis se construiu e se alicerçou no contraditório.

\section{ENTRE RIOS, RITOS, IDEOLOGIAS E MEMÓRIAS.}

Tudo mudou, ela acordou Estava onde nunca quis estar Engenheiros do Hawaii

Neste momento, será abordado o livro Quarto de hora, livro dividido em duas partes, uma composta pelo conto com o mesmo nome, que se subdivide em

VOL. 14 | N. 1 | JUN. 2017 ISSN 1415-7950

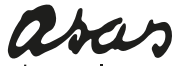

da palavra 
quatro parte, e a segunda parte intitulada Horas, formada por 14 pequenos contos, que parecem se agrupar para auxiliar ou rechaçar possíveis interpretações do livro. É interessante perceber como o livro todo tem uma relação encantatória, onde o ritual de passagem da primeira narrativa, acaba por permear os contos que se seguem.

A narrativa Quarto de Hora é a única produção de Maria Lucia Medeiros que poderia ser classificada como novela ${ }^{5}$, muito devido à quebra do horizonte de expectativa do que seria um conto, tanto na questão estrutural do gênero, quanto na questão tamanho, pois a narrativa se divide em quatro momentos, em que a estrutura se dissolve, em uma história poética de caráter cíclico, em que o ciclo da vida é explorado pela escritora.

O conto a todo momento surpreende o leitor ao ser conduzido por uma narradora autodiegética, que narra sua própria história, o que é interessante para se perceber as transformações que a narradora sofre, com cada rito que ela vivencia, transformando o conto em um conto ritual-mítico, onde as personagens passam por travessias, que são contadas por uma memória entrecortada.

No primeiro momento, observa-se a presença de um rito de passagem de transmissão do conhecimento (formação ideológica) entre a mãe e a filha; a jovem recebe da mãe a incumbência de se tornar a nova detentora do saber, das histórias de muito tempo atrás, que havia sido "transmudadas até os ouvidos de sua mãe" (MEDEIROS, 1994, p.11) e que agora era passada a filha. Histórias de uma "cidade toda branca à beira de um rio não tão largo, mas de verdade tão profundo e de águas muito escuras" (MEDEIROS, 1994, p.11). Nessa cidade, havia algo de estranho, pois as pessoas não se comunicavam, andavam sempre de cabeça baixa e tinham hábitos monarcas: "Os senhores zelavam por suas senhoras e as senhoras retribuíam zelo e proteção, encerrando-se no interior das casas a educar os filhos, ensinando-lhes, além de hábitos saudáveis, línguas mortas” (MEDEIROS, 1994, p.12).

Claramente, o texto narra a noção da ideologia da transmissão, onde ele defende que todo o conhecimento não pode estar restrito, ele deve ser dividido para que as histórias e fatos de uma sociedade não se percam. Dentro dessa ideologia da transmissão a mãe narra com a preocupação de que a filha entenda a história, que perceba a importância simbólica que está por trás dela, no entanto, a menina, por não possuir uma formação ideológica e social formada não consegue entender o que estava sendo dito pela mãe. Muito pelo fato da menina estar em transição de suas ideologias, na borda, no limiar; em que ela não é mais menina, porém ainda não se reconhecia como mulher, como se observa no fragmento:

O mercado lá no alto, as portas abertas, as pessoas, o cântico elevando-se pelas alturas provocavam em mim imagens de ovelhas sacrificadas, sangue a manchar o chão do mercado. Embora minha mãe não confirmasse as imagens, jamais deixei de tê-las. O sangue que eu inventava corria rubro a desenhar no chão estranhas formas. Embalde minha mãe tentou desconfirmar. Minha mãe, só hoje compreendo, temia por mim que queria com fragor saber o fim da história. (MEDEIROS, 1994, p. 13).

A mãe percebe esse limiar que a filha se encontra, e tenta dar tempo para ela "amadurecer", esse amadurecimento nasce da ideologia da transmissão, pois a menina amadurece suas ideologias, quando entra em contato com as ideologias de sua mãe, por meio do contar história em um longo espaço de tempo, deixando o final sempre para depois. "Assim, por muitos e muitos anos, acreditei ser esse o final da história.

5 Apesar de estar mais próximo da novela do que do conto, neste artigo, por uma questão de aproximação da autora ao seu gênero de oficio, referiremos à narrativa Quarto de Hora como conto.

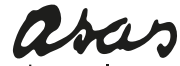

da palavra ISSN 1415-7950
A paciência bíblica de minha mãe fê-la esperar até que eu aprendesse a não sucumbir à passagem da beleza ou, em outras palavras dela, saber juntar lavra e colheita" (MEDEIROS, 1994, p.13).

A filha nesse momento passa por um despertar da sua ideologia como mulher, pois agora ela conhece os mistérios da vida.

Dentro de um discurso mítico, a lua é a figura principal do rito final de que a menina passa, pois a lua representa a esperança e o caminho da vida da personagem, em seguir adiante, porque "quando não há lua há paralisação da vida, não somente física, mas também social, geral ou especial, por conseguinte período de margem" (VAN GENNEP, 2013, p. 153).

A segunda parte do conto mostra a protagonista em sua juventude, agora 
sem mais a presença física da mãe, porém ainda guiada pela formação ideológica dela, buscando solucionar perguntas sem respostas deixadas pela mãe, ao mesmo tempo que busca encontrar a "si mesma".

Nem tive precisão de olhar para trás. Já era o dia seguinte e o Sol que me fizera despertar anunciava o dia pelo meio. Pus-me a caminho. Deparei-me dona, senhora de mim, possuinte dos meus próprios passos, sem saudades.

Apressei marcha e logo ultrapassei légua-limite, lancei-me. Eu parecia deslizar do topo do mundo o passo destravado para cumprir estirão que se perdia a frente dos meus olhos. (MEDEIROS, 1994, p.23).

Apesar de já se entender em outra fase da sua vida, percebe-se uma jovem em crise, novamente na margem, pois em vários momentos se dá conta que ainda não tem uma ideologia sua, e que precisa de outras pessoas para lhe auxiliar.

$\mathrm{Na}$ terceira parte, percebe-se que a crise se dissipa, pois, em busca das respostas deixadas por sua mãe, a jovem amadurece, adquire a maturidade ideológica para enfrentar seus problemas.

Na última parte do conto, a narradora já com maturidade suficiente, a narradora tem sua ideologia formada, e começa a entender os questionamentos deixados por sua mãe, e percebe que aqueles questionamentos são as incertezas que a vida nos deixa, inclusive se afastando da sua mãe para completar sua passagem. "Experimentei pensar em minha mãe, mas minha memória ainda não retemperada não a trazia mais, por maior que fosse o esforço em recobrá-la" (MEDEIROS, 1994, p. 34).

Chegando ao fim do conto a ideologia da transmissão do conhecimento se completa, onde a mesma história é vivida pela mãe e pela narradora, é transmitida de geração após geração, fazendo um movimento cíclico, mas que não é fechado. "Esperar o final é querer a história, é merecê-la pelo direito da espera, é possuir infinitamente, ad aeternum". (MEDEIROS, 1994, p.14), corroborando ao discurso de Bakhtin (2000) de que a ideologia perpassa e ganha novas significações.

\title{
3 ENTRE AS RUAS E OS RIOS QUE FLUTUAM NA MEMÓRIA DO VELHO HALIM E DA ÍNDIA DOMINGAS.
}

\author{
Esse rio é minha rua \\ Minha e tua, mururé \\ Piso no peito da lua \\ Deito no chão da maré \\ Paulo André Barata
}

Para compor esta parte da discussão, selecionou- se dois momentos do romance pós-moderno Dois Irmãos, com o intuito de comprovar o discurso memorialístico e mítico proposto na primeira parte desta escrita e como estes são usados no romance para justificar a ideologia de que toda prática discursiva é um ato social e os mitos e a rememorações são partes formadoras da ideologia discursiva de quem fala e de quem vivencia a realidade. Foucault (2013) alerta que a prática discursiva deve ser uma espécie de ritual social, este definido pelo filósofo francês como:

O ritual define a qualificação que devem possuir os individuos que falam. [...]; define os gestos os comportamentos, as circunstâncias, e o todo o conjunto de signos que deve acompanhar o discurso; fixa, enfim, a eficácia suposta ou imposta das palavras. [...]. Os discursos religiosos, judiciários, terapêuticos e, em parte, políticos, não podem ser dissociados dessa prática de um ritual que determina para os sujeitos que falam, ao mesmo tempo, propriedades singulares e papéis preestabelecidos. (FOUCAULT, 2013, p. 37). 
A partir da ideia de Foucault, percebe-se que essas práticas ritualísticas responsáveis por gerar os papéis preestabelecidos podem ser vistas no texto hatouniano; por este romance fazer parte da Literatura de expressão amazônica, já se espera que no decorrer do enredo, irá estabelecer uma relação do texto à realidade da região, caracterizada pelos:

mistérios da vida se expõem com naturalidade, o numinoso acompanha as experiências do cotidiano e os homens são eles ainda e ainda não os outros de si mesmos. Um tempo ainda jungido do sagrado e que resiste forte fragilmente a se tornar profano. Ao mesmo tempo, uma cultura que tende a ficar despedaçada no ar dessa história de cobiças da riqueza da terra, agravada nas últimas décadas, dos conflitos resultantes no extermínio ou dizimação de tribos, morte por encomenda, poluição dos rios, assassinato de cidades, voracidade do consumismo e de grandes extensões de florestas irremediavelmente queimadas (LOUREIRO, 2015, p. 16).

Isso se observa na fala do narrador do romance, quando apresenta a fala de seu avô Halim, quando o velho rememora a cidade de Manaus, desde seus aspectos mais caracterizadores, como o rio, os pescadores, os jogadores, a vida ribeirinha, mesmo em um ambiente citadino, que se encontra em destruição pela ocupação do processo de urbanização proposto pelo Governo Militar. Neste momento, há a destruição do espaço- água para a instauração do progresso. Na passagem do romance:

Numa tarde que ele escapara logo depois da sesta, eu o encontrei na beira do Rio Negro. Estava ao lado, cercado por pescadores [...]. Assistiam atônitos à demolição da cidade futuante. Tudo se desfez num só dia, o bairro desapareceu. [...] às vésperas do natal de 1968. Ele sabia que Manaus se tornara uma cidade ocupada. As escolas e os cinemas tinham sido fechados, lanchas da Marinha patrulhavam a baía do Negro, e as estações de rádio transmitiam comunicados do Comando Militar da Amazônia. (HATOUM, 2000, p. 198).

Oberva-se que a realidade amazônica descrita por Loureiro, principalmente em "assassinato de cidades, voracidade do consumismo e de grandes extensões de florestas irremediavelmente queimadas" (LOUREIRO, 2015, p.16), é uma realidade social também descrita pela Literatura, que é transmitida pelo narrador ao leitor por suas memórias individuais. No entanto, neste romance toda a narrativa é contada por Nael- o narrador- não só por suas reminiscências e suas sombras do passado, as quais remetem à memória, mas também por meio das lembranças de Halim e de Domingas, o que faz a prosa escrita por Hatoum, um texto memorialístico que permeia a memória coletiva, haja vista que elas estão nas circunstâncias das formações de lembranças do indivíduo, elas ajudam-no a recordá-las, "instante adoto seu ponto de vista, entro em seu grupo, do qual continuo a fazer parte, pois experimento ainda sua influência e encontro em mim muitas das ideias e maneiras de pensar a que não me teria elevado sozinho, pelas quais permaneço em contato com elas." (HALBWACHS, 2013, p. $31)$.

E o narrador ainda comprova que muitas das memórias que ele narra era de outros personagens, tanto Halim, constatado no excerto:

Parecia um sufi em êxtase quando me recitava cada par de versos rimados. Contemplava a folhagem verde e umedecida, e falava com força, a voz vindo de dentro, pronunciando cada sílaba daquela poesia, celebrando um instante do passado. Eu não compreendia os versos quando ele falava em árabe, mas ainda assim me emocionava: os sons eram fortes e as palavras vibravam com a entonação da voz. Eu gostava de ouvir 
as histórias. Hoje, a voz me chega aos ouvidos como sons da memória ardente. Às vezes ele se distraía e falava em árabe. Eu sorria, fazendo-lhe um gesto de incompreensão: "É bonito, mas não sei o que o Senhor está dizendo”. Ele me dava um tapinha na testa, murmurava: "É a velhice, a gente não escolhe a língua da velhice. Mas tu podes aprender umas palavrinhas, querido”. (HATOUM, 2000, p. 51).

Quanto nas falas da mãe do narrador: Domingas, como se verifica na passagem do romance: "Isso Domingas me contou. Mas muita coisa do que aconteceu eu mesmo vi, porque enxerguei de fora aquele pequeno mundo. Sim, de fora e às vezes distante. Mas fui o observador desse jogo e presenciei cartadas, até o lance final." (HATOUM, 2000, p. 29).

Nas duas últimas passagens citadas há a comprovação de que a memória individual do narrador está inserida intrinsecamente a memória coletiva dos outros que viveram com ele.

Outro aspecto oriundo da memória coletiva presente neste romance se diz a respeito dos discursos míticos, embora essa obra seja contextualizada em uma sociedade pós-moderna e capitalista, o mito se faz presente, isso se justifica porque o mito "me fala como reagir diante de certas crises de decepção, maravilhamento, fracasso ou sucesso diante da realidade, os mitos me dizem onde estou." (CAMPBELL, 1990, p. 16). E ele (o mito) aparece na narrativa hatouniana na fala da índia Domingas, e um dos mitos mais populares, o boto. No fragmento: "Na casa Zana foi a primeira a notar esse pendor do filho para o galanteio. Domingas também se deixava encantar por aquele olhar. Dizia: 'Esse gêmeo tem olhão de boto; se deixar ele leva todo mundo para o fundo do rio"”. (HATOUM, 2000, p. 30), Domingas compara o olhar sedutor do gêmeo Yaqub à ideia do mito do olhar sedutor do boto. Com isso, assim como os personagens dos contos de Inglês de Sousa e Maria Lúcia Medeiros, o texto de Hatoum não se priva de também usar um discurso voltado para o mito tão comum ao cenário social da Amazônia seja o do Estado do Pará, seja o de Manaus.

Por meio de seu texto, há também a ideologia de que o discurso mítico da Amazônia, não sobressaia ao discurso do imigrante árabe presente na fala das personagens, mas que se insere a ela como mais um elemento do discurso; o narrador e as demais personagens fazem uso do poder do mito amazônico e das tradições dos imigrantes, no caso do romance, árabes, para compor e justificar suas práticas e seus rituais preestabelecidos (FOUCAULT, 2013) dentro de seus discursos, isto é, não há uma ideologia discursiva sobreposta à outra, não há a ideologia do poder do discurso indígena de Domingas sobrepondo-se ao discurso do imigrante árabe de Halim, o que há são mesclas de culturas inseridas numa mesma realidade social sendo transmitidas pelos fios da memória do narrador do romance.

\section{CONSIDERAÇÕES FINAIS}

Diante das análises realizadas sobre os três textos selecionados para este estudo, conclui-se que as práticas discursivas estão a todo instante inseridas na realidade social em que são inclusas, e que também estão interligadas à ideologia de quem se apodera do discurso por alguma finalidade.

No caso dos estudos feitos para este trabalho, essas práticas foram empregadas por dois fins intrínsecos à realidade em que as tessituras foram desenvolvidas, a ideia do discurso mítico concernente à ideia dos ritos memorialísticos, ambos com o intuito de representar de certa forma a identidade das personagens que foram costuradas pelo viés dos narradores seja Luis do conto O rebelde de Inglês de Sousa, seja a de Quarto de Hora de Mária Lúcia Medeiros, seja Nael o do romance Dois Irmãos de Milton Hatoum.

Logo, o que se conclui é que os discursos e os relatos são usados conforme a realidade social e os ritos preestabelecidos por ela dentro de uma sociedade, visando a suas necessidades, incorporando as memórias individuais às práticas da coletividade, o discurso não permite ao indivíduo o isolamento, ele é parte de uma ideologia, 
e isso se deve ao fato do discurso ser caracterizado por seu aspecto social de poder como defendido por Foucault.

\section{REFERÊNCIAS}

BAKHTIN, M. Questões de literatura e de estética: a teoria do romance. Trad. A. F.Bernardini et al. São Paulo: Hucitec, 2002.

BOSI, Ecléa. Memória e sociedade, lembranças de velhos. 2. ed. São Paulo: T.A. QUEIROZ Ed. da USP, 1987.

CAMPBELL, Joseph. O herói de mil faces. São Paulo: Pensamento, 1997.

O poder do mito- entrevista com Bill Moyers. Trad. Carlos Felipe Moisés. São Paulo: Palas Athena, 1990.

COURTINE, J. J. O Chapéu de Clémentis. Observações sobre a memória e o esquecimento na enunciação do discurso político. In: INDURKY, Freda. (org.). Os múltiplos territórios da análise do discurso. Porto Alegre: Editora Sagra Luzzato. 1999.

FOUCAULT, M. A ordem do discurso. 23 ed. São Paulo: Edições Loyola, 2013. (Leituras Filosóficas).

HALBWACHS, Maurice. A memória coletiva. Trad. Beatriz Sidou. São Paulo: Centauro, 2013.

HALL, S. Quem precisa de identidade? In: SILVA, T.T. (org.), HALL, S., WOODWARD, K. Identidade e diferença: A perspectiva dos estudos culturais. Petrópolis: Vozes, 2000.

HATOUM, Milton. Dois Irmãos. São Paulo. Cia das Letras, 2000.

JAUSS, Hans Robert. A história da literatura como provocação à teoria literária. Trad. Sérgio Tellaroli. São Paulo: Ática, 1994. (Série Temas, v.36)

LOUREIRO, João de Jesus Paes. Cultura Amazônica: uma poética do imaginário. Belém: Cejup, 2015.

MEDEIROS, Maria Lúcia. Quarto de hora. Belém: Cejup, 1994.

NUNES, Benedito. O tempo na narrativa. São Paulo Edições Loyola, 2013.

PÊCHEUX, M. Papel da Memória. In: ACHARD, Pierre [et al.]. Papel da Memória. Campinas, São Paulo: Pontes, 1999.

SOUSA, Inglês de. Contos Amazônicos. São Paulo: Martin Claret, 2005.

VAN GENNEP, A. Os Ritos de Passagem. Trad. Mariano Ferreira. Rio de Janeiro, Vozes, 2013. 